\title{
Thermal Performance Prediction for Air Flow in a Wavy Corrugated Duct at Steady-State Constant Heat Flux Mode and Early Stages of Turbulent Flow Conditions
}

\author{
Ali H. Tarrad ${ }^{1 *}$, Damiaa S. Khudor ${ }^{2}$ \\ ${ }^{1}$ Université de Lorraine, CNRS, LEMTA, Nancy, France \\ ${ }^{2}$ Mechanical Engineering, College of Engineering, Al-Mustansiriya University, Baghdad 14150, Iraq \\ Corresponding Author Email: dr.alitarrad@mottaa.com
}

https://doi.org/10.18280/mmep.060415

Received: 4 July 2019

Accepted: 12 November 2019

\section{Keywords:}

enhancement, heat transfer, wavy surfaces, correlation, constant heat flux

\begin{abstract}
The present work represents an attempt to formulate the air heat transfer performance exhibited from a wavy corrugated duct in the form of simplified correlations at constant heat flux. The correlations are empirical formulae intended to be applied for a corrugation wavelength to amplitude ratio $(\lambda / \mathrm{a})$ of $(5.7-12.6)$ with $\left(0^{\circ}\right)$ phase shift angle at corrugation plate angles of $\left(54.5^{\circ}\right),\left(45^{\circ}\right),\left(38^{\circ}\right)$, and $\left(32.5^{\circ}\right)$. The main stream air flow Reynolds number domain through the corrugated duct was bounded by $\left(1.85 \times 10^{3}\right)$ to $\left(3.9 \times 10^{3}\right)$. Four simple correlations for the heat transfer coefficient enhancement factor, corrugated duct heat transfer coefficient, Stanton number and Nusselt number were developed by the implementation of the Buckingham-pi theorem. These correlations were in terms of the duct corrugation characteristics, flow operating conditions and exerted heat flux. The deviation of the predicted data for the heat transfer coefficient enhancement factor was within a scatter of $( \pm 10) \%$. The corrugated duct Stanton number, Nusselt number and heat transfer coefficient were correlated with accuracy margin of $( \pm 20) \%$ of the measured experimental data.
\end{abstract}

\section{INTRODUCTION}

The wavy corrugated surfaces are implemented for the industrial applications where the hydrodynamic measure is not a restriction and the thermal aspect is of a vital importance. A significant thermal enhancement may be attained depending on the operating conditions regarding Reynolds number, corrugation geometry configuration and heat flux.

Numerical investigations were conducted to investigate the heat transfer and pressure drop characteristics in a corrugated channel with the rounded angles [1-3]. The heat transfer rates for flow through a periodic array of wavy passages were studied [4]. The results of the average Nusselt numbers for the wavy wall channel didn't show much enhancement than those for a smooth channel. A numerical analysis was conducted for transitional characteristics of fluid flow and heat transfer in corrugated duct [5]. Computations were performed for Prandtl number of 0.7 , in the Reynolds number range of (100 to 2500), for corrugation angles of $\left(15^{\circ}\right)$ and $\left(30^{\circ}\right)$. They found that the predicted transitional Reynolds number was lower than the value for the parallel plate duct and it showed a decrease with increasing corrugation angle.

An experimental investigation has been conducted to study the flow behavior and local heat transfer for laminar and transitional flows in sinusoidal wavy passages [6]. They postulated that the heat transfer experiments confirmed that instabilities observed in the low visualization experiments result a heat transfer enhancement in the wavy channel. A numerical model was built to study laminar heat transfer in a channel with smooth and corrugated wall to determine the velocity and temperature distributions [7]. The results revealed that the optimum corrugated wall profile provides a nearly
(8) \% increment with respect to the heat dissipated by the optimum at wall profile.

Experimental investigation for the natural convection heat transfer variation through a square enclosure of $\mathrm{V}$-corrugated vertical plates by air stream was performed [8]. The results showed that the increase of mass flow rate increases the heat transfer rate and the decrease of water inlet temperature increases the heat transfer rate. The heat transfer characteristics and pressure drop in a channel of different corrugation angle exposed to a constant heat flux were investigated $[9,10]$. They concluded that the heat transfer was tremendously enhanced and great pressure drop deterioration was noticed when compared to those of parallel plate channel for laminar as well as turbulent flows.

A numerical scheme was presented to investigate the heat transfer and fluid flow characteristics in a wavy corrugated plate channels in the laminar flow regime [11]. The corrugated wall structure only maximizes the heat transfer when both the Reynolds and Prandtl numbers are not too low. A numerical study for a two-dimensional steady fluid flow and heat transfer through a periodic wavy passage was conducted [12]. Experimental study was achieved to investigate the heat transfer characteristics and air friction factor for fully developed flow of air and water plate heat exchanger [13]. The test corrugation angle was $\left(30^{\circ}\right)$ for air flow Reynolds number range from (16900) to (68000). Various correlations for the Nusselt and friction factor were obtained in this work.

A numerical investigation for the trend of heat transfer and flow field through a two dimensional wavy duct was accomplished [14]. The results showed that by making the waves to be sharper, the heat transfer mechanism will be more powerful and the average Nusselt number will be increased 
along the length of the duct.

A numerical study for the fluid flow and heat transfer in the entrance region in a converging-diverging channel with sinusoidal wall corrugations was performed [15]. They concluded that the variations of the amplitude of channel plates and the Reynolds number have an important effect on the dynamic growth of the low field.

Numerical computation models were postulated for air cooling heat transfer and flow behaviors in triangular wavy fin channels [16]. Within the range of simulation, the results showed that the heat transfer enhancement was fin structure parameters dependent such as wavelength, wave amplitude and phase shift angle. The correlations of both heat transfer factor and friction factor were presented, and the deviations from the experimental measurements to be within (20) \% for the Reynolds number range of (200) to (3000). Experimental investigation was achieved to study the flow structure in the corrugated channel [17]. The study focused on the hydrodynamics of flow in the corrugated channels using the Particle Image Velocimetry (PIV) technique for Reynolds numbers of (4000) and (6000). More recently, Dimensional analysis was used to establish a model for prediction of the mono-ethanolamine heat exchangers output [18]. The Buckingham pi theorem and the method of repeating variables were implemented to predict the outlet temperature of known operating conditions for such heat exchangers. The simulation model was evaluated by comparing predicted results against measured rich amine exit temperatures. In this respect, (98.96) \% correlation, (0.023) \% mean absolute percentage error and $1.376 \mathrm{~K}$ maximum absolute error were achieved.

The previous work of many researchers showed that the experimental or numerical investigations were conducted at either high or low Reynolds number range [5, 13-17]. Further, a narrow range of corrugation angles was experimentally or numerically utilized in these researches. In the present study, the experimental data collected from cooling of four pairs of heated corrugated and one plain wall in a duct structure were correlated at a narrow range of Reynolds number. The corrugated plates have four different angles of $\left(54.5^{\circ}, 45^{\circ}, 38^{\circ}\right.$, and $32.5^{\circ}$ ) measured from x-axis under constant heat flux conditions. These corrugation angles are corresponding to a wavelength to amplitude ratio $(\lambda / \mathrm{a})$ of $(5.7-12.6)$. All of these surfaces were examined at $\left(0^{\circ}\right)$ phase shift angle for the corrugated plates. A narrow range of Reynolds number bounded by the laminar, transition and turbulent flow regimes was implemented. A number of correlation forms for the air heat transfer performance are suggested and formulated by using a dimensional analysis based on the Buckingham-pi theorem.

\section{AVAILABLE CORRELATIONS}

The heat transfer rate achieved from corrugated or finned surfaces is quite a difficult task and it is hard to be handled with a single general formula. This is due to the many parameters that control the heat transfer and hydrodynamic phenomena. Such parameters represent the fin geometry and distribution, flow characteristic, Reynolds number and heat flux. According to the intended application purpose, the parameters are selected to be implemented for the description of the process by the researcher. Therefore, the majority of the available correlations are limited by their application to fulfill the conditions of their creation.
A correlation was postulated for the prediction of the Nusselt number and heat transfer coefficient enhancement efficiency for a V-shape corrugation plate [19]:

$$
\Gamma=\left.\frac{h_{t}}{h_{p}}\right|_{p p}=6.31 R e_{t}^{-0.227}(P R)^{-0.0012}
$$

And the Nusselt numbers is expressed as:

$$
N u=0.37 \operatorname{Re}_{t}^{0.635} \operatorname{Pr}^{0.4}(P R)^{-0.22}
$$

where,

$$
P R=1+S \quad S=\frac{s}{D} \quad \text { and } \quad R e_{t}=\frac{u D}{v}
$$

The above correlations are valid for $\mathrm{PR}=2,4$ and 7 in the Reynolds number range (8000) and (18000). They postulated that the majority of the measured data fall within $( \pm 10) \%$ for their correlation of Nusselt number.

A correlation for the heat transfer factor based on a numerical analysis for corrugated channels was suggested [16]. It has the following form:

$$
j=0.6399 R e^{-0.4467} F_{h}{ }^{0.0231} F_{p}^{0.3463} a^{0.096} \lambda^{-0.075} L^{-0.371}
$$

The Reynolds number $(R e)$ was defined as:

$$
R e=\frac{u D_{h}}{v}
$$

$D_{h}$ represents the hydraulic diameter of the fin channels employed for the fluid flow in the simulation model. The correlation predicted the experimental measurements within (20) \%. It is applied for the Reynolds number range from (200 to 3000 ) and following the configuration conditions:

$F_{\mathrm{h}}=8,9$, and $10 \mathrm{~mm} \quad F_{\mathrm{p}}=2,2.5,3,3.5$, and $4 \mathrm{~mm} \quad a=$ (1.0-1.2) $\mathrm{mm}, L=(70-140) \mathrm{mm} \quad \lambda=10,14,17.5,25$, and 35 $\mathrm{mm}$

Compared with those of straight fins, the simulation results showed that the triangular wavy fin channels exhibited higher heat transfer performances especially with fin structural parameters of $F_{\mathrm{h}}=9 \mathrm{~mm}, F_{\mathrm{p}}=2.5-3 \mathrm{~mm}, \lambda=(14-17.5) \mathrm{mm}$ and $a=1-1.2 \mathrm{~mm}$.

\section{PRESENT CORRELATIONS}

\subsection{Overview}

The previous works have emphasized the importance of the fin geometry configuration and operating conditions in the thermal and hydrodynamic assessment of the flow in corrugated channels $[9,10,14-16,18,19]$. Accordingly, the heat transfer coefficient enhancement factor of corrugated surfaces can be represented by these measures. These variables include the corrugation geometry, flow characteristics and operating conditions of the flow as:

1- The physical geometry parameters of the corrugated surface to include the wavelength $(\lambda)$, wave amplitude $(a)$ and corrugation angle $(\alpha)$ in radians 
2- Flow and thermal characteristics throughout the duct which can be represented by the flow velocity $(u)$ and fluid physical properties, $(\mu),(\rho),(c p)$ and $(k)$, and

3 - The operating heat flux exerted at the heating surface and the main stream ability to absorb it, is represented by $(\dot{q})$.

Subsequently, the following parameters were considered as the major variables to represent the present frame work of the suggested correlations:

$$
\varphi=\varphi(\rho, \mu, c p, k, u, \lambda, a, \alpha, \dot{q})
$$

Here $(\varphi)$ represents any of the considered dependent variables in the present work.

\subsection{Present correlation derivative}

\subsubsection{Enhancement factor}

In performing the dimensional analysis of the present work, the well-known Buckingham pi theorem was implemented for this purpose. Four dimensions for these variables $(M, L, T, \theta)$ together with four selected governing variables $(\rho, u, c p, \lambda)$ will be considered. There are ten variables, $\left(\eta_{h}, \rho, \mu, c p, k, u, \lambda, a, \alpha, \dot{q}\right)$ expressed in terms of four fundamental dimensions. The objective of such formula is to find an expression which relates $\left(\eta_{h}\right)$ to other independent variables. Therefore, the expression relating the variables will contain six independent dimensionless groups including the enhancement or deterioration factors in the forms:

$$
\begin{aligned}
& \pi_{1}=\eta_{h} \\
& \pi_{2}=R e_{\lambda}=\frac{\rho u \lambda}{\mu} \\
& \pi_{3}=\frac{k}{\rho u c p \lambda} \\
& \pi_{4}=\frac{\lambda}{a} \\
& \pi_{5}=\frac{\dot{q}}{\rho u^{3}} \\
& \pi_{6}=\alpha
\end{aligned}
$$

Hence, the suggested correlations should have the following expression:

$$
\pi_{1}=\psi\left(\pi_{2}, \pi_{3}, \pi_{4}, \pi_{5}, \pi_{6}\right)
$$

where, $(\psi)$ represents a function of the independent dimensionless groups, then

$$
\eta_{h}=\psi\left\{R e_{\lambda},\left(\frac{k}{\rho u c p \lambda}\right),\left(\frac{\lambda}{a}\right),\left(\frac{\dot{q}}{\rho u^{3}}\right), \alpha\right\}
$$

This function may be represented in an expression having the form:

$$
\eta_{h}=C \operatorname{Re}_{\lambda}{ }^{m}\left(\frac{k}{\rho u c p \lambda}\right)^{n}\left(\frac{\lambda}{a}\right)^{i}\left(\frac{\dot{q}}{\rho u^{3}}\right)^{j} \alpha^{l}
$$

Here, $\left(\eta_{h}\right)$ represents the thermal measure defined as follows:

$$
\eta_{h}=\frac{h_{\text {Corrugated }}}{h_{\text {Smooth }}}
$$

The indices $(m),(n),(i),(j)$ and $(l)$ are numerical values to be determined from experimental data measured at specified operating conditions. These constants may be determined from the best fit to the experimental data which reveals a minimum deviation and residual.

\subsubsection{Heat transfer measures}

In a similar manner; another correlation was developed to predict the air side heat transfer coefficient in a corrugated surface in analogy to the expression shown in Eq. (13). Here, the air heat transfer coefficient $(h)$ was considered to be the dependent parameter of the variables shown in Eq. (4). Then the Buckingham-pi theorem revealed that the first dimensionless group $\left(\pi_{1}\right)$ has the form of the well-known Stanton number as:

$$
\pi_{1}=\frac{h}{\rho u c p}
$$

This yields a general formula as:

$$
S t=C \operatorname{Re}_{\lambda}{ }^{m}\left(\frac{k}{\rho u c p \lambda}\right)^{n}\left(\frac{\lambda}{a}\right)^{i}\left(\frac{\dot{q}}{\rho u^{3}}\right)^{j} \alpha^{l}
$$

Here (St) is the Stanton number of air flow measured at the main stream velocity and fluid properties through the duct. The indices of this correlation could be obtained from experimental data according to the operating conditions of the air flow inside the duct. The Stanton number of the present correlation may be written in terms of its original definition as:

$$
S t=\frac{N u_{\lambda}}{R e_{\lambda} P r}=C\left(\pi_{2}\right)^{m}\left(\pi_{3}\right)^{n}\left(\pi_{4}\right)^{i}\left(\pi_{5}\right)^{j}\left(\pi_{6}\right)^{l}
$$

Hence

$$
N u_{\lambda}=\frac{h \lambda}{k}=C \operatorname{Pr}\left(\pi_{2}\right)^{m+1}\left(\pi_{3}\right)^{n}\left(\pi_{4}\right)^{i}\left(\pi_{5}\right)^{j}\left(\pi_{6}\right)^{l}
$$

Most of the air medium practical applications reveal that the Prandtl number is almost a constant value of (0.7). Then the above expression can be represented as:

$$
N u_{\lambda}=\frac{h \lambda}{k}=0.7 C\left(\pi_{2}\right)^{m+1}\left(\pi_{3}\right)^{n}\left(\pi_{4}\right)^{i}\left(\pi_{5}\right)^{j}\left(\pi_{6}\right)^{l}
$$

Then the final expression of the Nusselt number is represented by:

$$
N u_{\lambda}=\frac{h \lambda}{k}=0.7 C R e_{\lambda}{ }^{m+1}\left(\frac{k}{\rho u c p \lambda}\right)^{n}\left(\frac{\lambda}{a}\right)^{i}\left(\frac{\dot{q}}{\rho u^{3}}\right)^{j} \alpha^{l}
$$

The expression of the heat transfer coefficient achieved from the flow inside a corrugated duct may be expressed as:

$$
h=\frac{N u_{\lambda} k}{\lambda}=0.7 \frac{k}{\lambda} C R e_{\lambda}^{m+1}\left(\frac{k}{\rho u c p \lambda}\right)^{n}\left(\frac{\lambda}{a}\right)^{i}\left(\frac{\dot{q}}{\rho u^{3}}\right)^{j} \alpha^{l}
$$

It should be pointed out that the indices of the dimensionless groups to be determined from experimental data at specified operating conditions of the air flow through the duct. 


\subsection{Formulae physical explanation}

The physical meaning of the present dimensionless groups is represented by the variables those constitute their forms. The first group $\left(\pi_{1}\right)$ is already defined by Eq. (14) and Eq. (15) for the heat transfer enhancement factor and heat transfer coefficient assessments respectively. The independent group $\left(\pi_{2}\right)$ represents a modified Reynolds number of the flow to be based on the corrugation wavelength and main stream air velocity. Group $\left(\pi_{3}\right)$ is a sort of the Stanton number of the main air stream in terms of the corrugation wavelength and flow physical properties. The corrugation physical effect is represented by the groups $\left(\pi_{4}\right)$ and $\left(\pi_{6}\right)$. Group $\left(\pi_{4}\right)$ represents the intensity and compactness degree of the corrugation distribution to construct a corrugated surface. It is higher for the higher corrugation angle and number of corrugation waves.

Group $\left(\pi_{6}\right)$ refers to the corrugation angle which represents how far the corrugated geometry is away from the plain plate performance. As noticed from the experimental data, increasing of this angle increases the turbulence of the flow adjacent to the wall and hence enhances the heat transfer and deteriorates the flow pressure drop. The physical indication of group $\left(\pi_{5}\right)$ is the ability of the flow to absorb the exerted power at the heating surface by the convection mode under the steady state conditions.

It should be pointed out that the heat transfer enhancement factor and pressure drop have a strong assessment relation. It is axiomatic that the enhancement of the heat transfer aspect exhibited a reflected penalty for the hydrodynamic characteristics. Hence a compromise should be considered for the extent to which each aspect could affect the overall performance of the corrugated surface. Therefore, enhanced surfaces are of economic industrial application when the hydrodynamic aspect is not a factor.

\section{EXPERIMENTAL WORK}

The coefficient and indices of Eq. (13) and Eq. (16) are to be inferred from experimental data conducted on corrugated channels. The data collected from the experimental setup, test section and instrumentation shown in Figure 1 as presented by [20].

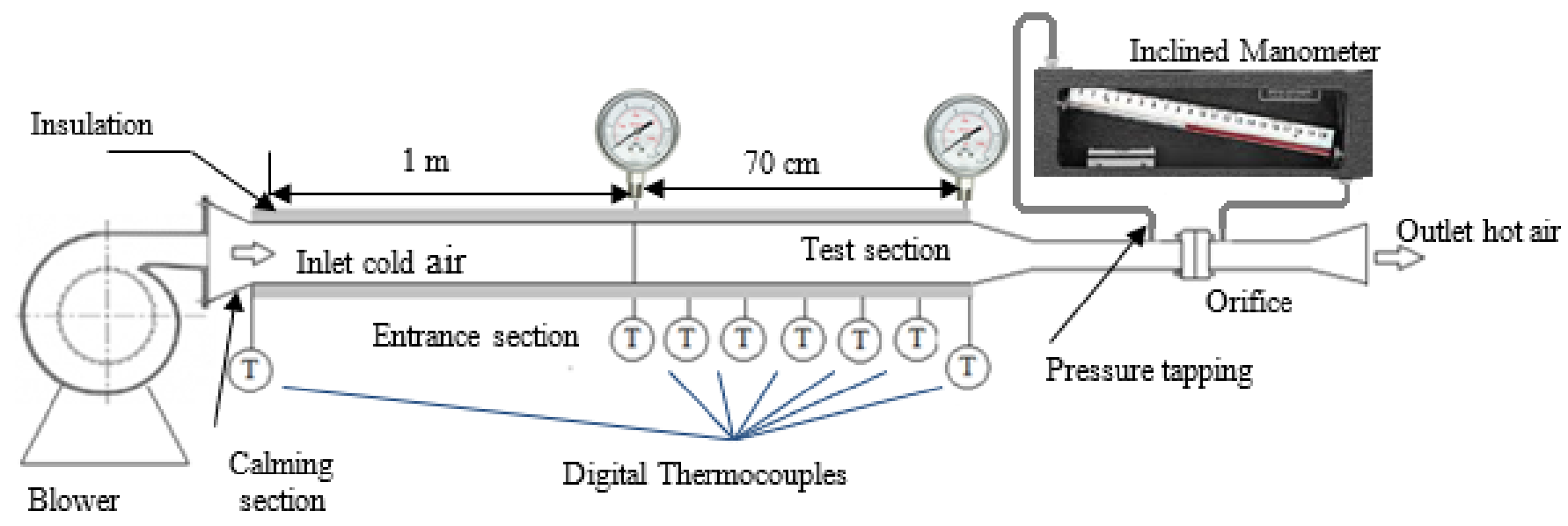

Figure 1. A schematic diagram of experimental setup, [20]

\subsection{Test setup}

The test rig consists of entrance section, a test section, orifice, and outlet air portion. The air stream flows from a (5) $\mathrm{kW}$ blower and then passed through a calming section duct made of a conical section having $\left(75^{\circ}\right)$ angle with horizontal. This was aimed to damp the turbulence in flow, assure stability and helps smoothing of pressure fluctuations in the entering air stream. It passes through the heat transfer test section, orifice meter to measure the air flow rate, and then discharged to the atmosphere.

\subsection{Test section}

The test section was a corrugated channel with two opposite corrugated plates on both of the upper and lower sides of the duct arranged in a $\left(0^{\circ}\right)$ phase shift angle. The air duct is a square cross section having dimensions of $(10 \times 10) \mathrm{cm}$ and an effective length of $(70) \mathrm{cm}$, Figure 2 . The corrugated part of the duct was made of a metal sheet having a width of (10) $\mathrm{cm}$ and a length of (1.12) $\mathrm{m}$. The wavy corrugated plate metal was made of (0.5) $\mathrm{mm}$ thick and (7) $\mathrm{mm}$ corrugation height aluminum sheet. The corrugated sheet was fitted tightly with the wall by compression to prevent its movement and air leakage. The duct was insulated with (2) inch fiberglass standard blanket to minimize the heat loss from shell to the ambient. The corrugated sheet was heated by a flexible electrical wire affixed firmly at the plate capable to provide a uniform heat flux boundary condition.

Four different corrugated plates were tested; they were classified according to their wavelength $(\lambda)$ in the air flow direction, Table 1 . The electrical output power was controlled by a variac transformer to obtain a constant heat flux along the entire length of the test section. Measurements for the voltage $(V)$ and current $(I)$ passing through the heating element were recorded during the tests. The surface area of the corrugated plates was (60) \% bigger than that of the flat one. Therefore, the supplied power of the heating element was adjusted to attain the constant heat flux target. To ensure the reproducibility of the experimental data, it was decided to repeat each test for (3) times under the same system operating conditions. In this way, the recorded data for the assessment of this investigation will ensure its compatibility and confidence with minimized error margin. 


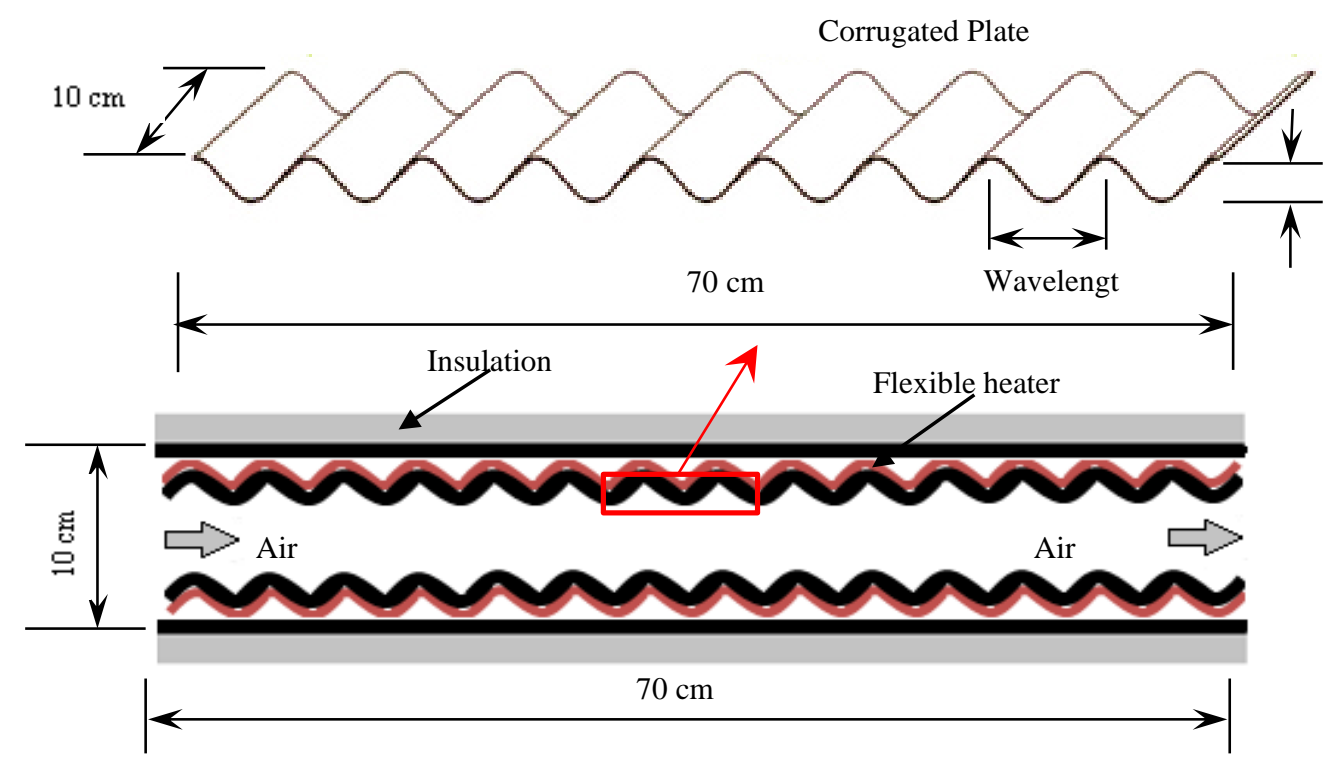

Figure 2. A schematic diagram shows the geometry characteristics of the test section [20]

Table 1. A detailed dimensions of the Aluminum test corrugated duct [20]

\begin{tabular}{|c|c|c|c|c|c|c|c|c|c|}
\hline \multirow{2}{*}{ Plate Parameter } & \multicolumn{9}{|c|}{ Dimension } \\
\cline { 2 - 10 } & $\begin{array}{c}\mathbf{L} \\
(\mathbf{c m})\end{array}$ & $\begin{array}{c}\mathbf{W} \\
(\mathbf{c m})\end{array}$ & $\begin{array}{c}\mathbf{A} \\
\left(\mathbf{m}^{2}\right)\end{array}$ & $\begin{array}{c}\mathbf{N} \\
(---)\end{array}$ & $\begin{array}{c}\boldsymbol{\alpha} \\
\left({ }^{\circ}\right)\end{array}$ & $\begin{array}{c}\boldsymbol{\lambda} \\
(\mathbf{m m})\end{array}$ & $\begin{array}{c}\mathbf{Z} \\
(\mathbf{c m})\end{array}$ & $\begin{array}{c}\mathbf{a} \\
(\mathbf{m m})\end{array}$ & $\begin{array}{c}\lambda \boldsymbol{a} \\
(---)\end{array}$ \\
\hline Case 1 & 70 & 10 & 0.112 & 70 & $54.5^{\circ}$ & 20 & 10 & 3.5 & 5.7 \\
\hline Case 2 & 70 & 10 & 0.112 & 50 & $45^{\circ}$ & 28 & 10 & 3.5 & 8 \\
\hline Case 3 & 70 & 10 & 0.112 & 38 & $38^{\circ}$ & 36 & 10 & 3.5 & 10.3 \\
\hline Case 4 & 70 & 10 & 0.112 & 32 & $32.5^{\circ}$ & 44 & 10 & 3.5 & 12.6 \\
\hline
\end{tabular}

\subsection{Measurements uncertainty}

A high precaution was taken to the accuracy of the measurement due to the low values of power used during tests. The outer surface of the experimental rig was almost perfectly insulated with a (2) inch glass wool sheet. All of the thermocouples were calibrated to provide an error percentage of the measurement to be within $(0.1) \%$ on full scale. The uncertainty of the digital measuring instrument for the voltage and current passing through the heating element was less than (0.1) \% according to the manufacturer. The accuracy of the air flow measurement of (1) \% was considered, which represented the highest uncertainty of the measurement instrumentation. The above measures revealed uncertainty for the measured data to lie within $( \pm 2) \%$, [20].

\subsection{Test operating conditions}

The test conditions of the present work are related to the flow and heat flux limitations. The air mass flow rate was ranged between (12.6) and (40.6) $\mathrm{kg} / \mathrm{hr}$ at entering air temperature of (40-41) ${ }^{\circ} \mathrm{C}$. Air flows inside duct with entering air velocity range between $(0.3)$ and $(0.67) \mathrm{m} / \mathrm{s}$ measured at the main air stream. This reveals a corresponding narrow Reynolds number range from $\left(1.85 \times 10^{3}\right)$ to $\left(3.9 \times 10^{3}\right)$ respectively. Three different low heat fluxes were implemented during experiments namely, (500), (750) and (1000) $\mathrm{W} / \mathrm{m}^{2}$. Seven K-type thermocouples were embedded along the test section wall at equal spacing. It was necessary to measure the temperature at (7) stations at the surface of the heat transfer test section for the thermal assessment objectives. Similarly, (7) K-type copper-constantan thermocouples with an accuracy of $(0.1) \%$ of full scale were employed to measure air dry bulb temperature distributed at the same distances as the wall ones at the center of the duct. This procedure produced a heat transfer coefficient distribution in the air flow direction at (7) positions along the test section.

\subsection{Experimental data range}

\subsubsection{Typical experimental data}

The data were collected for series of experiments conducted at variety of operating conditions and corrugated surface configurations by [20]. Typical data for the comparison of variation of heat transfer coefficient with flow Reynolds number and various corrugation angles at heat fluxes of (1000 and 500) $\mathrm{W} / \mathrm{m}^{2}$ is shown in Figure 3.

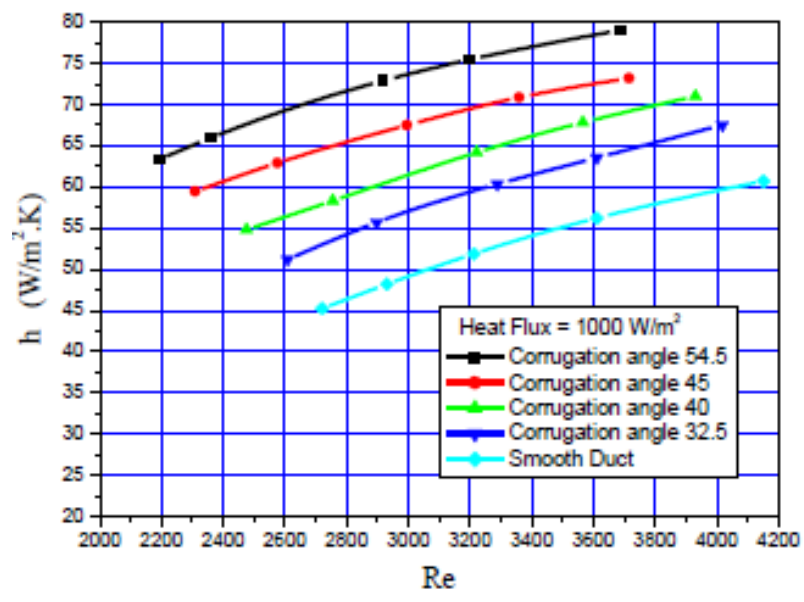

(a) Heat flux of (1000) W/m² 


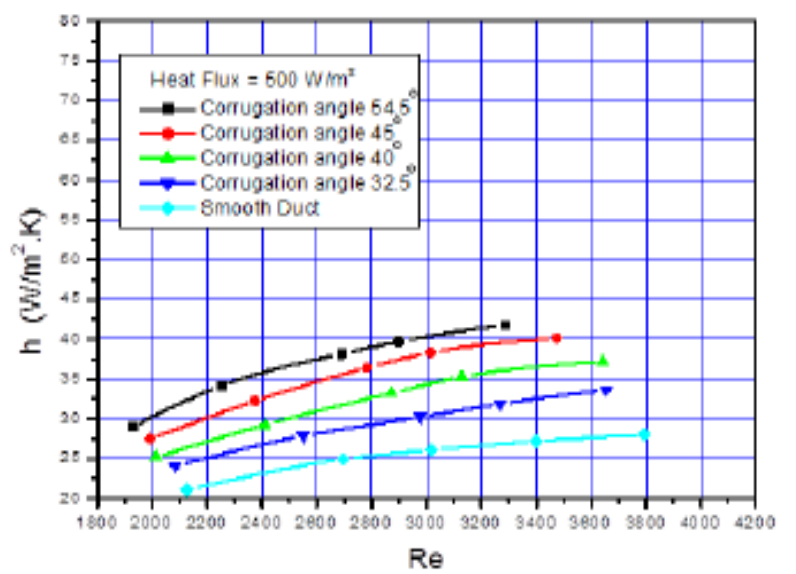

(b) Heat flux of (500) W/m²

Figure 3. A comparison for the heat transfer coefficient exhibited by test surfaces, [20]

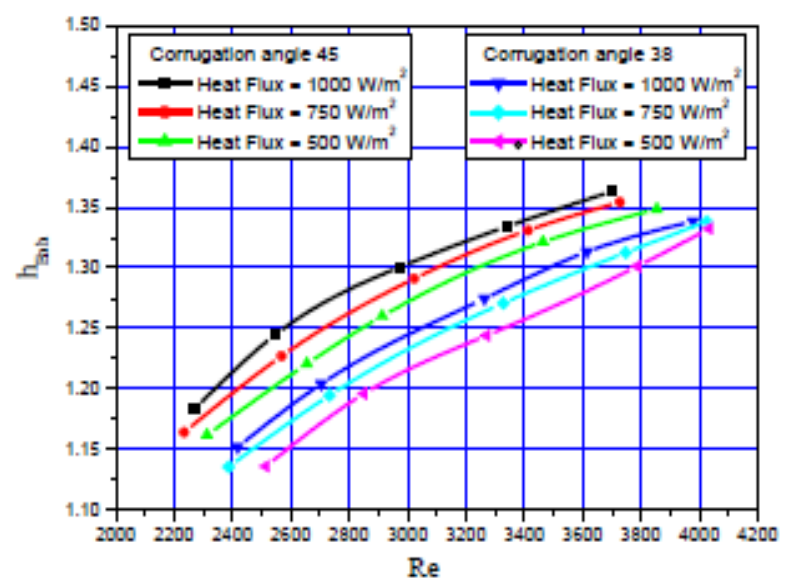

(a) Corrugation angles $45^{\circ}$ and $38^{\circ}$

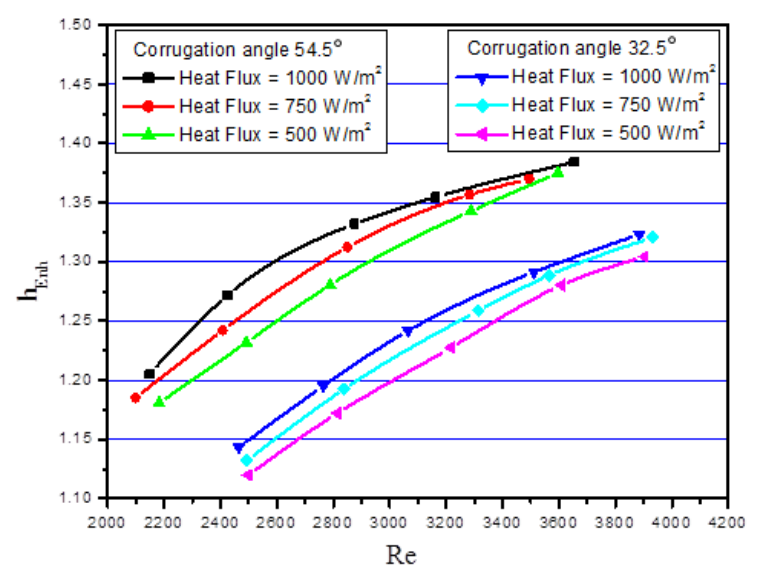

(b) Corrugation angles $54.5^{\circ}$ and $32.5^{\circ}$

Figure 4. Comparison of thermal enhancement factor at various corrugation angles and heat fluxes, [20]

A comparison for the enhancement factor of heat transfer coefficient at the four test corrugation angles obtained for the whole test heat fluxes is shown in Figure 4. The experimental data showed that heat transfer coefficient and enhancement factor revealed an increase with Reynolds number, heat flux and corrugation angle.

\subsubsection{Validation of correlations}

Enhancement factors of (1.1) to (1.4) in heat transfer coefficient for the wavy plate structures were exhibited at the test heat fluxes. These values correspond to enhancement percentages of (11) \% to (39) \% for heat transfer coefficients. The extent to which heat transfer coefficient augmented depends on the corrugation angle, Reynolds number and exerted heat flux. More details of the experimental work and data assessment are available [20].

The accomplished correlations in the present work have the following limitation conditions regardless of the dependent parameter:

$$
\begin{array}{rr}
500 \leq \dot{q} \leq 1000 & 400 \leq R e_{\lambda} \leq 1760 \\
12.6 & 0.57 \leq \alpha \leq 0.95
\end{array}
$$

These conditions were assigned for the present correlations due to the limits of operating conditions which were considered for the experimental work.

\section{CONSTANTS DETERMINATION}

\subsection{Thermal enhancement factor $\left(\boldsymbol{\eta}_{h}\right)$}

The above experimental data was implemented to determine the required constant and indices for the present correlation shown in Eq. (13).

$$
\eta_{h}=0.01033\left(R e_{\lambda}\right)^{1.242}\left(\frac{k}{\rho u c p \lambda}\right)^{0.767}\left(\frac{\lambda}{a}\right)^{0.640}\left(\frac{\dot{q}}{\rho u^{3}}\right)^{0.0574}(\alpha)^{1.822}
$$

These coefficient and indices showed the best prediction to be with average absolute residual of (0.05). This correlation revealed that the standard deviation of the fitting is (0.065). This formula shows that the enhancement factor is proportional to the corrugation angle, Reynolds number and to less extent to the exerted heat flux as proved by the experimental data [20].

Eq. (22) showed the direct proportionality of the behavior of $\left(\eta_{h}\right)$ with the dimensionless groups stated on the right-hand side of the correlations. It is a well responded to the variation of these parameters as those obtained from the experimental data. This correlation predicted the thermal parameter within acceptable uncertainty and showed excellent agreement with test data.

\subsection{Heat transfer coefficient}

The correlation for this category showed the following expression for the best fit of the experimental data:

$$
S t=C \frac{\left(\pi_{2}\right)^{m}\left(\pi_{3}\right)^{n}\left(\pi_{5}\right)^{j}\left(\pi_{6}\right)^{l}}{\left(\pi_{4}\right)^{i}}
$$

In which the coefficient and indices are as follows:

$$
S t=0.943 \times 10^{-8} \times C_{S t}\left(R e_{\lambda}\right)^{1.7842}
$$

where,

$$
C_{S t}=\left(\frac{k}{\rho u c p \lambda}\right)^{0.0848}\left(\frac{\lambda}{a}\right)^{-0.5371}\left(\frac{\dot{q}}{\rho u^{3}}\right)^{0.7185} \alpha^{1.9494}
$$

The average absolute residual and standard deviation of the fitting of the measured data are (0.0083) and (0.0124) 
respectively. Finally, the Nusselt number expression shown in Equation (20) has the following form:

$$
N u_{\lambda}=0.66 \times 10^{-8} \times C_{S t}\left(R e_{\lambda}\right)^{2.7842}
$$

Hence the air side heat transfer coefficient exhibited from the flow throughout the corrugated duct under constant heat flux can be expressed as:

$$
h=0.66 \times 10^{-8}\left(\frac{k}{\lambda}\right) \times C_{S t}\left(R e_{\lambda}\right)^{2.7842}
$$

The predicted heat transfer coefficient for the air flow through the corrugated duct as presented by Eq. (27) showed its proportionality to the different parameters considered in its creation. This is shown by the strong response to the Reynolds number, heat flux and corrugation angle as validated by the experimental data utilized in their extraction.

\section{RESULTS AND DISCUSSIONS}

The validation of the present correlations stated in Eqns. (22-27) can be inferred from the experimental data and its prediction. The produced error or accuracy of the present correlations was assessed according to the following expression:

$$
\Phi^{\mp} \%=\frac{(\Phi \text { predicted-Фexperimental })}{\Phi \text { experimental }} \times 100
$$

where, ( $\Phi)$ refers to the parameter considered in the expression.

\subsection{Enhancement factor}

It is obvious that the enhancement factor of the heat transfer coefficient shown in Eq. (22), exhibited an augmentation with the increase of heat flux, Reynolds number and corrugation angle. Further, the higher of these values achieved the higher enhancement factor for the air flow stream. This is mainly due to the improvement of the flow regime and circulation in the vicinity of the corrugated channel. Figure 4 revealed that for a fixed corrugation angle, the heat flux has a little influence on the enhancement factor. The present correlation revealed a proper response to the measured data in regards to the exerted heat flux.

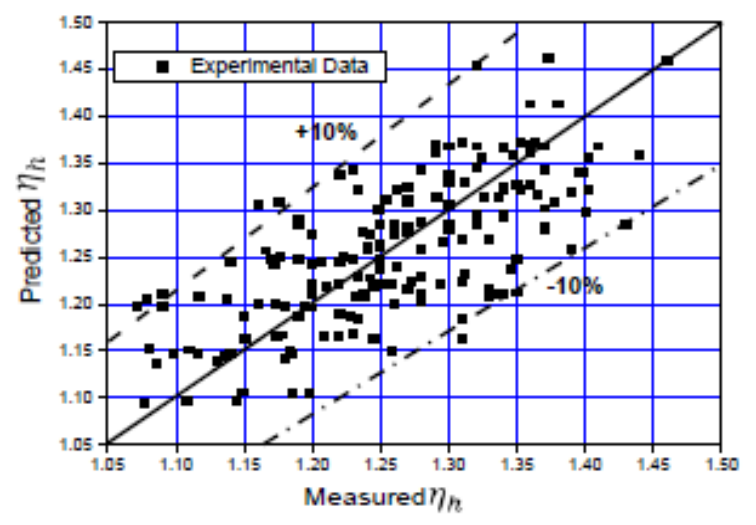

Figure 5. A comparison of the heat transfer coefficient enhancement factor between the present correlation and measured values
Figure 5 illustrates the comparison for the heat transfer coefficient enhancement factor between the predicted data and that measured in the tests. The present correlation revealed that its prediction lies in the scatter of $( \pm 10) \%$ for more than (97) $\%$ of the data points implemented in the present expression. Further, the present correlation showed a smooth response to the imposed operating conditions in regards to heat flux, air velocity and thermal properties of air flow as revealed by the corresponding numerical values of the enhancement factor. Hence, the physical interpretation of the present correlation revealed the right choice of the independent variables which control the heat transfer enhancement obtained by the corrugated surface.

The residual distribution of the heat transfer coefficient enhancement correlation is shown in Figure 6. The correlation has revealed an average error of $\left(1.184 \times 10^{-3}\right)$ represented by the red line.

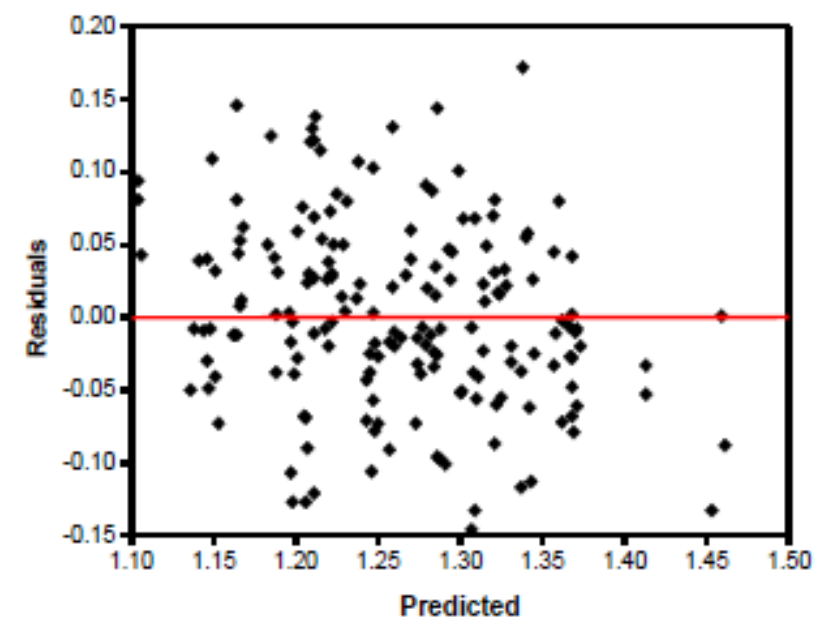

Figure 6. The heat transfer coefficient enhancement correlation residual distribution with predicted value

\subsection{Wavy surface correlations}

\subsubsection{Stanton number}

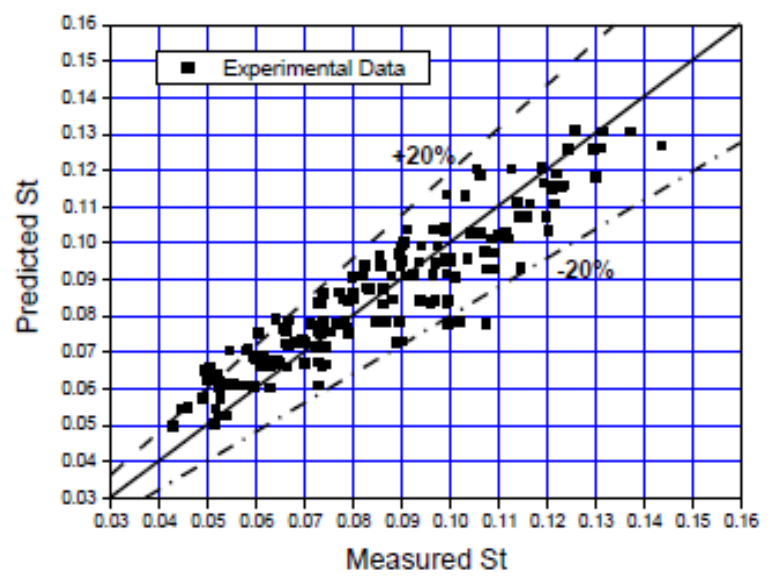

Figure 7. A comparison of the Stanton number

The Stanton number correlation illustrated in Eq. (20) was implemented to show the uncertainty when compared to the measured values. The present correlation reveals an acceptable error margin to be within $( \pm 20) \%$ for the vast majority of the data points as shown in Figure 7. It is worth mentioning that 
the numerical values of the Stanton number are quite small. This is mainly due to the low values of air heat transfer coefficient in the early stages of the turbulent flow regime. This could be explained by the strong relation between the flow Reynolds number and associated Nusselt number or heat transfer coefficient. In general, Stanton number for air flow possesses a low value at the test Reynolds number range of the present work [20].

The variation of the residual distribution of Stanton number with that obtained from the above correlation is shown in Figure 8 with an average error of $\left(-3.786 \times 10^{-5}\right)$.

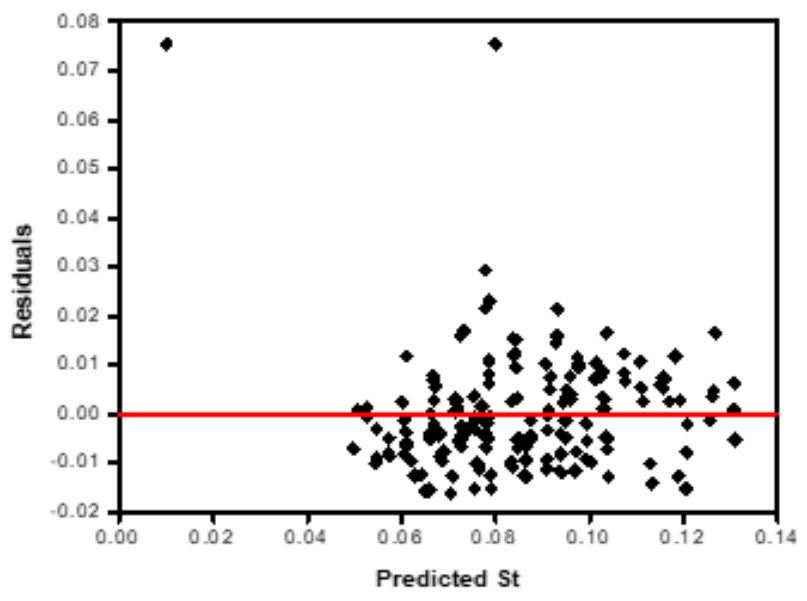

Figure 8. The variation of residuals with predicted values of Stanton number

\subsubsection{Nusselt number}

The modified Nusselt number shown in Eq. (21) is implemented in the prediction of the measured data of the corrugated surfaces. This comparison is shown in Figure 9 and has uncertainty margin to be within $( \pm 20) \%$ for the entire range of the test operating conditions. It is obvious that the vast majority of the predicted data bounded by the above uncertainty envelop. The trend of the predicted Nusselt number data showed a similar behavior as that of the measured values from the point of view of the response to the various parameters considered in the present correlation.

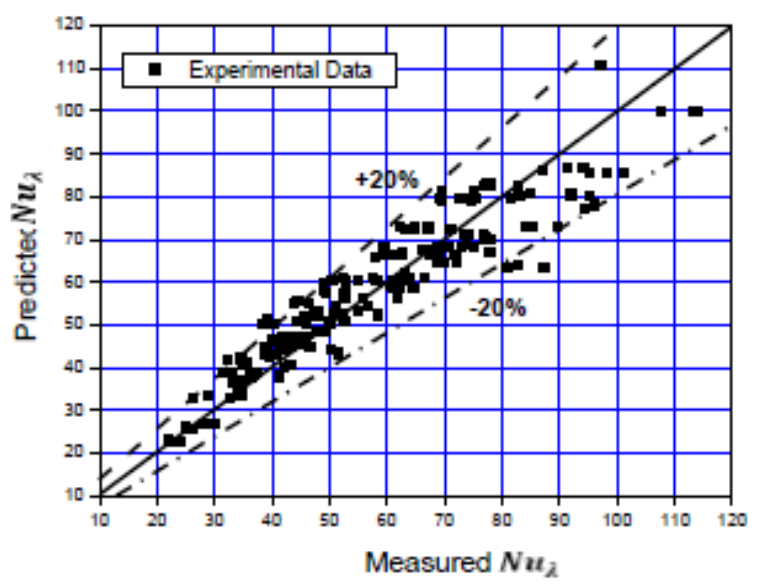

Figure 9. A comparison of the Nusselt number

\subsubsection{Heat transfer coefficient}

The predicted heat transfer coefficient exhibited from the corrugated duct is illustrated in Figure 10.
Investigating Figure 3 reveals that the achieved heat transfer coefficient exhibited a strong dependency on heat flux, Reynolds number, corrugation angle and surface corrugation geometry.

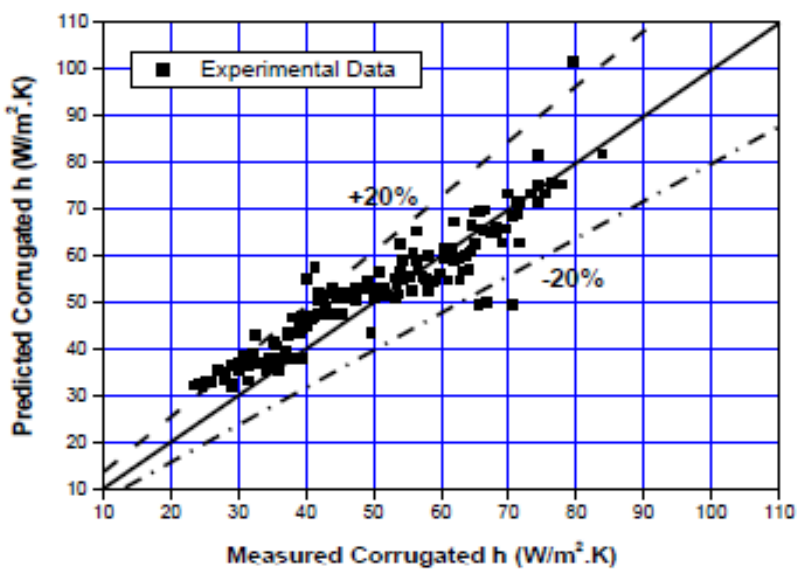

Figure 10. A comparison of the heat transfer coefficient

It is obvious that the enhancement factor increases as these measures increase and vice versa. This behavior is clearly shown by the response of the developed correlation to the variety of measures considered in its construction. The correlation showed acceptable agreement with the experimental data to fall within $( \pm 20) \%$ for the majority experimental data employed for the correlation creation. The correlation exhibited a standard deviation of (0.077) for the whole range of test operating conditions. The predicted corrugated heat transfer coefficient revealed an acceptable response to the various parameters and showed a good agreement with that of the experimental data.

\section{CONCLUSIONS}

The present work has revealed the following findings:

1- A steady state dimensional analysis of the thermal assessments in a corrugated duct have been correlated at Reynolds number range $\left(1.85 \times 10^{3}-3.9 \times 10^{3}\right)$ and low heat fluxes of (500), (750) and (1000) W/m².

2- The correlations are intended to be implemented for a corrugation wavelength to amplitude ratio $(\lambda / \mathrm{a})$ of (5.7-12.6) with $\left(0^{\circ}\right)$ phase shift angle at corrugation plate angles of $\left(54.5^{\circ}\right),\left(45^{\circ}\right),\left(38^{\circ}\right)$, and $\left(32.5^{\circ}\right)$.

3 - The experimental data showed that heat transfer coefficient and enhancement factor exhibited an increase with Reynolds number, heat flux and corrugation angle.

4- The heat transfer coefficient enhancement factor of the corrugated duct showed excellent agreement with those of the measured data within accuracy limit of $( \pm 10) \%$.

5- The Stanton number, Nusselt number and heat transfer coefficient have been correlated for the air flow inside corrugated duct to be with $( \pm 20) \%$ of the experimental data.

6- The dependent variables of the present correlations showed excellent response to the selected independent parameters in their formulation and consistency with the measured experimental data. 


\section{REFERENCES}

[1] Asako, Y., Nakamura, H., Faghri, M. (1986). Heat transfer and drop characteristics in a convergingdiverging round corners. Originally Published in Transactions of JSME, 52(477): 2170-2176.

[2] Asako, Y., Faghri, M. (1987). Finite volume solutions for laminar flow and heat transfer in a corrugated duct. J. of Heat 109: 627-634. http://dx.doi.org/10.1115/1.3248134

[3] Asako, Y., Nakamura, H., Faghri, M. (1988). Heat transfer and drop characteristics in a corrugated duct with rounded corners. Int. J. Heat and Mass Transfer, 31: 1237-1244.

[4] Wang, G., Vanka, S.P. (1995). Convective heat transfer in periodic wavy passages. Int. J. Heat Mass Transfer, 38(38): 3219-3230. http://dx.doi.org/10.1016/00179310(95)00051-A

[5] Yang, L.C., Asako, Y., Yamaguchi, Y., Faghri, M. (1997). Numerical prediction of transitional characteristics of flow and heat transfer in a corrugated duct. Journal of Heat Transfer, 119(1): 62-69. http://dx.doi.org/10.1115/1.2824101

[6] Rush, T.A., Newell, T.A., Jacobi, A.M. (1999). An experimental study of flow and heat and transfer in wavy passages. Int. J. Heat Mass Transfer, 42: 1541-1553. http://dx.doi.org/10.1016/S0017-9310(98)00264-6

[7] Fabri, G. (2000). Heat transfer optimization in corrugated wall channels. International Journal of Heat and Mass Transfer, 43: 4299-4310. http://dx.doi.org/10.1016/S0017-9310(00)00054-5

[8] Ali, M., Hasanuzzaman, M. (2006). Heat transfer by natural convection through $\mathrm{V}$-corrugated plates. Journal of Mechanical Engineering, 36: 1-5. https://doi.org/10.3329/jme.v36i0.804

[9] Layek, A., Saini, J.S., Solanki, S.C. (2006). Heat transfer and friction characteristics of solar air heater having compound turbulators on absorber plate. In: Proceeding of the 1st National Conference on Advances in Energy Research (AER 2006), Mumbai, pp. 188-194.

[10] Naphon, P. (2007). Effect of corrugated plates in an inphase arrange on the heat transfer and flow developments. International Journal of Heat and Mass Transfer, 51(1516): 3963-3971 https://doi.org/10.1016/j.ijheatmasstransfer.2007.11.050

[11] Paisarn, N. (2009). Effect of wavy plate geometry configurations on the temperature and flow distributions. International Communications in Heat and Mass Transfer, 36(9): 942-946. https://doi.org/10.1016/j.icheatmasstransfer.2009.05.00 7

[12] Bahaidarah, H.M. (2009). Fluid flow and heat transfer characteristic in sharp edge wavy channels with horizontal pitch. Emirates Journal for Engineering Research, 14(1): 53-63.

[13] Pandey, S.D., Nema, V.K. (2011). Experimental investigation of heat transfer and friction factor in a corrugated plate heat exchanger. International Journal of Energy and Environment, 2(2): 287-296.

[14] Zonouz, O.N., Salmanpour, M. (2012). Numerical analysis of flow field and heat transfer of 2D wavy ducts and optimization by Entropy generation minimization method. Journal of Thermodynamics, 2012: 8 pages. http://dx.doi.org/10.1155/2012/574596

[15] Mohamed, N., Wided, B.R., Mohamed, E.M., El karim, M.A., Mohamed, B. (2013). Numerical investigation on the fluid flow and heat transfer in the entrance region of wavy channel. Energy Procedia, 36: 76-85. http://dx.doi.org/10.1016/j.egypro.2013.07.010

[16] Long, N.M., Ping, C.Y., Cong, D., Feng, W.J. (2014). Numerical simulation of heat transfer and flow of cooling air in triangular wavy fin channels . J. Cent. South Univ., 21: 2759-2765. http://dx.doi.org/10.1007/s11771-0142238-3

[17] Tokgoz, N., Aksoy, M.M., Şahin, B. (2016). Experimental investigation of flow characteristic of corrugated channel flow using PIV. Journal of Thermal $\begin{array}{lll}\text { Engineering, } & \text { 2(2): }\end{array}$ http://dx.doi.org/10.18186/jte.34504

[18] Sánchez-Escalona, A.A, Góngora-Leyva, E., CamarazaMedina, Y. (2019). Monoethanolamine heat exchangers modeling Using the Buckingham pi theorem. Mathematical Modelling of Engineering Problems, 6(2):197-202. https://doi.org/10.18280/mmep.060207

[19] Promvonge, P., Eiamsa-ard, S. (2007). Heat transfer augmentation in a circular tube using V-nozzle turbulator inserts and snail entry. Experimental Thermal and Fluid Science, 32: 332-340. http://dx.doi.org/10.1016/j.expthermflusci.2007.04.010

[20] Tarrad, A.H., Khudor, D.S. (2017). Experimental assessment for sinusoidal wavy corrugated channels at early stages of turbulent flow. International Journal of Engineering Technology and Management (IJETM), 4(3): $1-12$.

\section{NOMENCLATURES}

A: $\quad$ Corrugated duct surface area, $\mathrm{m}^{2}$

a: $\quad$ Corrugation wavelength, $\mathrm{mm}$

$C$ : $\quad$ Constant of proportionality defined in (12)

cp: $\quad$ Air specific heat, $\mathrm{J} / \mathrm{kg}$. K

D: $\quad$ Tube diameter, $\mathrm{mm}$

$F_{h}: \quad$ Fin height, mm

$F_{p}: \quad$ Fin pitch, mm

$h$ : $\quad$ Heat transfer coefficient, $\mathrm{W} / \mathrm{m}^{2} . \mathrm{K}$

$j: \quad$ Heat transfer factor defined in (3)

$k$ : $\quad$ Thermal conductivity, W/ m. K

$L: \quad$ Fin-length in mm or length unit, $\mathrm{m}$

M: $\quad$ Mass unit, $\mathrm{kg}$

$N: \quad$ Number of corrugations, Dimensionless

$\mathrm{Nu}$ : Nusselt number, Dimensionless

Pr: $\quad$ Prandtl number, Dimensionless

PR: $\quad$ Pitch ratio, Dimensionless

$\dot{q}: \quad$ Heat flux, $\mathrm{W} / \mathrm{m}^{2}$

Re: $\quad$ Reynolds number, Dimensionless

$s: \quad$ Free-space length between turbulators, $\mathrm{mm}$

S: $\quad$ Space ratio, Dimensionless

St: $\quad$ Stanton number, Dimensionless

T: $\quad$ Time unit, $\mathrm{s}$

$u$ : $\quad$ Air flow velocity, $\mathrm{m} / \mathrm{s}$

$W: \quad$ Corrugated duct height, $\mathrm{m}$

$Z$ : $\quad$ Corrugated duct width, $\mathrm{cm}$ 


\section{Greek letters}

$\alpha$ : $\quad$ Corrugation angle measured from horizontal axis $\left(^{\circ}\right)$ or $(\mathrm{rad})$

$\Gamma$ : $\quad$ Heat transfer coefficient enhancement at constant pumping power, Dimensionless

$\eta_{h:} \quad$ Heat transfer coefficient enhancement factor,

$\theta: \quad$ Demperature unit, $\mathrm{K}$

$\lambda$ : $\quad$ Corrugation wavelength, $\mathrm{mm}$ $\mu$ : $\quad$ Air dynamic viscosity, Pa.s

$v \quad$ Kinematic viscosity, $\mathrm{m}^{2} / \mathrm{s}$

$\rho: \quad$ Air density, $\mathrm{kg} / \mathrm{m}^{3}$

$\phi: \quad$ Air relative humidity, $\%$

\section{Subscripts}

h: $\quad$ Hydraulic value

$p$ : $\quad$ Measured for plain surface

$t$ : $\quad$ Measured for duct with turbulators

$\lambda$ : $\quad$ Calculation based on the wavelength parameter 